\title{
A Noise-Insensitive Semi-Active Air Suspension for Heavy-Duty Vehicles with an Integrated Fuzzy-Wheelbase Preview Control
}

\author{
Zhengchao Xie, Pak Kin Wong, Jing Zhao, Tao Xu, Ka In Wong, and Hang Cheong Wong \\ Department of Electromechanical Engineering, University of Macau, Taipa, Macau, China \\ Correspondence should be addressed to Jing Zhao; zhaojing003@gmail.com
}

Received 21 April 2013; Accepted 4 June 2013

Academic Editor: Qingsong Xu

Copyright ( 2013 Zhengchao Xie et al. This is an open access article distributed under the Creative Commons Attribution License, which permits unrestricted use, distribution, and reproduction in any medium, provided the original work is properly cited.

\begin{abstract}
Semi-active air suspension is increasingly used on heavy-duty vehicles due to its capabilities of consuming less power and low cost and providing better ride quality. In this study, a new low cost but effective approach, fuzzy-wheelbase preview controller with wavelet denoising filter (FPW), is developed for semi-active air suspension system. A semi-active suspension system with a rolling lobe air spring is firstly modeled and a novel front axle vertical acceleration-based road prediction model is constructed. By adopting a sensor on the front axle, the road prediction model can predict more reliable road information for the rear wheel. After filtering useless signal noise, the proposed FPW can generate a noise-insensitive control damping force. Simulation results show that the ride quality, the road holding, the handling capability, the road friendliness, and the comprehensive performance of the semi-active air suspension with FPW outperform those with the traditional active suspension with PID-wheelbase preview controller (APP). It can also be seen that, with the addition of the wavelet filter, the impact of sensor noise on the suspension performance can be minimized.
\end{abstract}

\section{Introduction}

Suspension is one of the main components of a vehicle. Its role is to provide ride comfort for passengers, to offer road holding and competent handling capabilities, and to give support to the vehicle static weight [1]. Comparing to active suspension and passive suspension, semi-active suspension is currently the most popular type of vehicle suspension as it has the best compromise between the performance (handling, ride comfort, safety, etc.) and cost (sensors, weight, components, electronics, power consumption, etc.) $[2,3]$. A semi-active suspension system generally consists of springs and some variable dampers that are controlled by various algorithms or controllers such that the damping coefficient can be adjusted instantly. In recent, air springs have been introduced in heavy-duty vehicles because they can effectively attenuate the effects of the disturbance from the road input and easily adjust the ride height on board. When air springs are used instead of conventional steel springs, the semi-active suspension system is also called a semi-active air suspension system, which is the case of this study.
In the current literature, many control algorithms for semi-active suspension have been introduced. The most common approach for both academic and industrial applications is the sky-hook (SH) damping control, which was first introduced by Crosby et al. [4]. Many researches on SH control [5-8] have been carried out as it provides an easy way to obtain good suspension performance. The SH control has also been extended to heavy-duty vehicles [9] and some enhanced SH control strategies [10-13] can still be found in recent years for more effective suspension improvement. Another ordinary example of suspension control algorithms is the ground-hook control strategy [14, 15], which can reduce the suspension deflection and increase the damping simultaneously. Other than these two methods, several nonlinear control techniques were also introduced recently, such as model predictive control [16-18] and the human simulated intelligent control [19]. However, the actuator of a semi-active suspension is actually a dissipation device which cannot be easily described by sets of differential equations, while an accurate and precise mathematical model is always required for those control techniques. Moreover, some parameters in the model are difficult to identify in real practice. Therefore, 
some artificial intelligence approaches have been applied to the semi-active suspension systems too as these approaches rely less on mathematical models. For instance, Hashiyama et al. used genetic algorithm to generate a fuzzy-based semi-active suspension controller [20]. Yoshimura et al. [21] proposed a semi-active controller using fuzzy reasoning. A neural-network-based fuzzy controller was also proposed by Eslaminasab et al. [22] to improve the suspension performance of heavy-duty vehicles. These studies showed that artificial intelligence approaches are very favorable for semiactive suspension control. As a result, this study also attempts to apply fuzzy logic-based controller to control the semiactive air suspension system.

Nevertheless, the existing fuzzy controller for semi-active suspension systems can only improve one performance, the road holding or handling capabilities. However, these two factors should be considered together. In order to deal with the ride quality, a strategy known as the preview control is adopted in this study. The principle of preview control is to predict the road condition for the rear wheel based on the road information obtained from the front of the vehicle so that the control action can be performed without too much delay. This idea was firstly introduced by Bender [23] and was then proved by several studies [24-29] to be a very promising approach with the use of hydraulic active suspensions. In general, two types of preview methods are available, namely, the front preview and the wheelbase preview [26]. For the first one, a road measurement sensor is placed in the front of the vehicle so that the road information can be obtained a few meters ahead of the two front wheels, whereas for the latter one, the road profile for the rear wheels is the road information obtained based on the displacement of the front wheels with a time delay [27]. In the semi-active suspension systems, wheelbase preview strategy is viewed as a low-cost solution because it only controls the rear suspension so as to save the number of variable dampers and sensors and control hardware for the front suspension.

Since more expensive sensors and accessories are required for the front preview, the wheelbase preview method is chosen for this research. The wheelbase preview control may not be better than the front preview, but the wheelbase preview control can at least provide an alternative and low-cost solution to the chassis engineer to choose. Nevertheless, in the existing wheelbase preview control strategy, the preview information is obtained by the vertical acceleration of the sprung mass in the front wheel. However, the vertical acceleration of the axle (or the unsprung mass) is actually more reliable than the vertical acceleration of the sprung mass in reflecting the road roughness as the latter one may be affected by the high frequency vibration of the spring and the damper [30]. Hence, the recent literature proved that sensors placed on the front axle should be more useful and convincing for the measurement of road roughness. With the application of the improved road measuring method, the road prediction process differs from the traditional one. Therefore, a new road prediction model that can handle the relationship between the vertical acceleration of front axle and the road input of rear wheel is demonstrated in this study as well.
Besides, during the road measuring process of traditional wheelbase preview method (and so as the front preview), all the state variables are assumed to be measured without any noise, yet the noise disturbance from the sensors during measurement cannot usually be avoided The noise disturbance, in fact, greatly influences the performance of the suspension system. Therefore, in order to improve the robustness of the system against noise, a wavelet denoising filter, or the so-called wavelet transform [31], is employed to filter out the useless measurement noise in the proposed semi-active air suspension. The wavelet transform is very suitable for nonstationary signal. Recent studies already applied this technique to isolate the automotive engine noise for signal analysis [32] and proved it to be superior to traditional denoising method such as Fourier analysis [33]. Hence, with the use of wavelet transform, fuzzy controller, and the new measurement idea in the wheelbase preview control, this paper proposes a new semi-active suspension with fuzzypreview control and wavelet filter (SFPW).

The rest of this paper is organized as follows. Section 2 presents the general idea of the proposed controller. For the construction of a preview model, a half-vehicle model equipped with a semi-active air suspension system is then created in Section 3. As the springs used are air springs, a nonlinear rolling lobe air spring model is designed in this section too. Then for simulation purpose, a road input model is required. It is described in detail along with the novel road prediction model in Section 4. In Section 5, the proposed SPFW for semi-active air suspension system is described in detail. The controller can control not only the tire deflection, but also the sprung mass acceleration so that the semi-active damping force can be adjusted constantly for better ride comfort and road holding capacity. In fact, no existing work has integrated a fuzzy controller to semi-active air suspension with wheelbase preview control, and none of the previous studies has included the external signal correction between the fuzzy and preview controllers before the generation of the semi-active damping force. Moreover, the proposed SFPW is simulated under the environment of heavy-duty vehicles with semi-active suspensions. Therefore, this is an original research to deal with such issues in this area. In order to show effectiveness of the wavelet filter and wheelbase preview controller, a fuzzy-wheelbase preview controller without wavelet filter (SFP) and a sole fuzzy controller (SF) are employed, respectively, in the same semi-active suspension as comparisons. Also, to verify the superior performance of the proposed SFPW method with previous research, a traditional active suspension with PID-wheelbase preview controller (APP) [24] is introduced as the third comparison type. The corresponding results and analysis are discussed in Section 6, and a conclusion is provided in Section 7.

\section{Proposed SPFW System}

The purpose of the proposed SFPW is to control some variable dampers in the suspension system properly so as to provide comfort for passengers, eliminate the road damage, and protect the freight. In general, the rear suspensions 


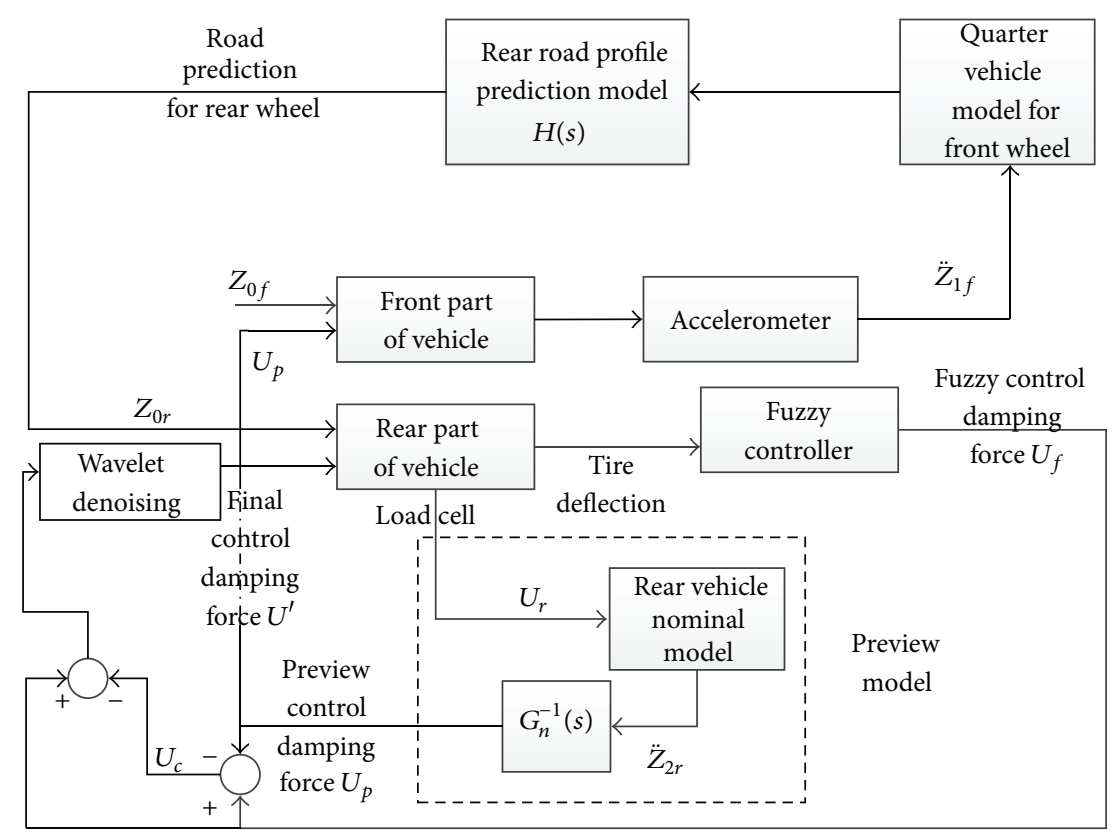

FIGURE 1: Schematic diagram of fuzzy-wheelbase preview control method.

undertake the main load of the heavy-duty vehicle, so the tire deflection and sprung mass acceleration are found in the rear wheels seriously. Therefore, reducing the tire deflection and optimizing the sprung mass acceleration are more desired than only concerning the sprung mass acceleration for the rear suspensions. Consequently, the proposed SFPW mainly consists of three parts-the preview model, the fuzzy controller, and the wavelet denosing filter. The preview model aims to optimize the sprung mass acceleration (i.e., the ride comfort) for front and rear suspensions, and the fuzzy controller deals with the tire deflection of the rear suspension, whereas the wavelet denoising filter suppresses the useless noise for producing a noise-insensitive control damping force. The schematic diagram of the proposed SFPW is depicted in Figure 1, in which the road input $Z_{0 f}$ is firstly provided to the front wheel of the vehicle.

With an accelerometer equipped on the front unsprung mass, the vertical acceleration can be detected, and then the road prediction model (Section 3.2) can predict the road information $Z_{0 r}$ for the rear wheel. With the predicted road profile, the damping force of the rear suspension $U_{r}$ can be measured from the load cell, which is used as the input of the preview nominal model, then the sprung mass acceleration of rear suspension $\ddot{Z}_{2 r}$ can be obtained, and finally the preview control damping force $U_{p}$ for the rear suspension can then be determined using $G_{n}^{-1}(s)$. The preview control damping force is then forwarded as two equivalent output signals. One is sent to the front variable damper of the suspension system as its control damping force, and the other one is sent as an external correction signal for the fuzzy controller output.

Apart from the preview control damping force, the tire deflection and its derivative from the rear part of the vehicle are entered to the fuzzy controller. The controller then, based on the fuzzy rules, provides a fuzzy control damping force $U_{f}$. After that, this force is combined with the aforementioned external correction signal of the preview control damping force $U_{p}$, and an initial correction signal $U_{c}$ is obtained. In consideration of the accuracy and stability of the final control damping force, the initial correction signal is then combined with the fuzzy control damping force $U_{f}$ again, and the output of the above two signals is sent to the wavelet denoising filter. After filtering the useless noise, the final control damping force $U^{\prime}$ is then delivered to the rear variable damper to adjust the damping force of the rear suspension.

\section{Half-Vehicle Modeling for Preview Control}

3.1. Half Vehicle Model with Semi-Active Air Suspension System. There are currently two types of heavy-duty vehicle suspension models available in the literature. One is unconnected type and the other is connected type [34]. As the application of the air spring is usually found in the unconnected type, this research mainly focuses on the unconnected suspension. Since it is quite difficult to implement this proposed system on a real vehicle to test, computer simulation is employed to demonstrate the effectiveness of the proposed system. To simplify the simulation, a halfvehicle model is considered in this research. The free body diagram of a half vehicle with unconnected suspension is shown in Figure 2. The dot on the vehicle mass is the static equilibrium position. In the semi-active suspension system, the control damping force in each wheel is provided by the corresponding variable damper.

Considering the dot as the origin of the displacement of the mass center and the angular displacement of the vehicle 


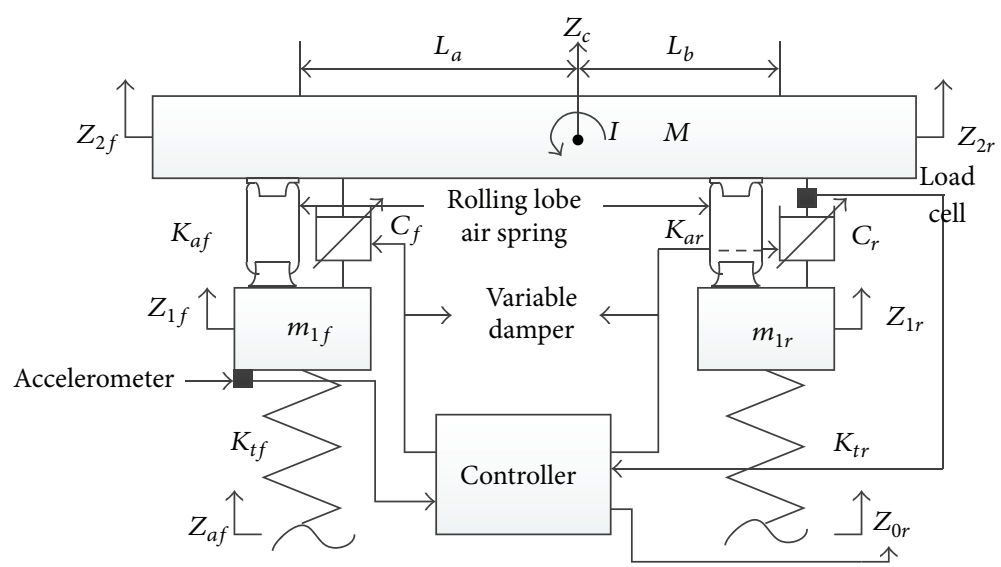

FIGURE 2: Half-vehicle model with semi-active air suspension.

body, the equations of motion for the front and rear unsprung masses are, respectively.

$$
\begin{aligned}
m_{1 f} \ddot{Z}_{1 f}= & K_{t f}\left(Z_{0 f}-Z_{1 f}\right) \\
& -K_{a f} \cdot\left(Z_{1 f}-Z_{2 f}\right)-C_{f}\left(\dot{Z}_{1 f}-\dot{Z}_{2 f}\right) \\
m_{1 r} \ddot{Z}_{1 r}= & K_{t r}\left(Z_{0 r}-Z_{1 r}\right) \\
& -K_{a r} \cdot\left(Z_{1 r}-Z_{2 r}\right)-C_{r}\left(\dot{Z}_{1 r}-\dot{Z}_{2 r}\right)-U_{p}
\end{aligned}
$$

where $U_{p}$ is the wheelbase preview control damping force in rear wheel vehicle.

Moreover, the equations of linear motion and angular motion of the whole vehicle body are.

$$
\begin{aligned}
M \ddot{Z}_{c}= & -K_{a f}\left(Z_{2 f}-Z_{1 f}\right)-K_{a r}\left(Z_{2 r}-Z_{1 r}\right) \\
& -C_{f}\left(\dot{Z}_{2 f}-\dot{Z}_{1 f}\right)-C_{r}\left(\dot{Z}_{2 r}-\dot{Z}_{1 r}\right)+U_{p}, \\
I \ddot{\theta}= & L a\left[K_{a f}\left(Z_{2 f}-Z_{1 f}\right)+C_{f}\left(\dot{Z}_{2 f}-\dot{Z}_{1 f}\right)\right] \\
& -L b\left[K_{a r}\left(Z_{2 r}-Z_{1 r}\right)+C_{r}\left(\dot{Z}_{2 r}-\dot{Z}_{1 r}\right)-U_{p}\right] .
\end{aligned}
$$

When the pitch angle $\theta$ is assumed to be very small, the displacement equations of front and rear sprung mass displacement are

$$
\begin{aligned}
& Z_{2 f}=Z_{c}-L_{a} \theta, \\
& Z_{2 r}=Z_{c}+L_{b} \theta .
\end{aligned}
$$

$\theta$ and $Z_{c}$ in (4) can be obtained as.

$$
\begin{gathered}
\theta=\frac{Z_{2 r}-Z_{2 f}}{L_{a}+L_{b}}, \\
Z_{c}=\frac{L_{a} Z_{2 r}+L_{b} Z_{2 f}}{L_{a}+L_{b}} .
\end{gathered}
$$

Then, by combining (2) and (5), the accelerations of the front and rear sprung mass can be reformulated as follows:

$$
\begin{aligned}
\ddot{Z}_{2 f}= & \left(\frac{1}{M}+\frac{L_{a}^{2}}{I}\right)\left[K_{a f}\left(Z_{1 f}-Z_{2 f}\right)+C_{f}\left(\dot{Z}_{1 f}-\dot{Z}_{2 f}\right)\right] \\
& +\left(\frac{1}{M}-\frac{L_{a} \cdot L_{b}}{I}\right)\left[K_{a r}\left(Z_{1 r}-Z_{2 r}\right)+C_{r}\left(\dot{Z}_{2}-\dot{Z}_{r}\right)\right] \\
\ddot{Z}_{2 r}= & \left(\frac{1}{M}-\frac{L_{a} \cdot L_{b}}{I}\right)\left[K_{a f}\left(Z_{1 f}-Z_{2 f}\right)+C_{f}\left(\dot{Z}_{1 f}-\dot{Z}_{2 f}\right)\right] \\
& +\left(\frac{1}{M}+\frac{L_{b}^{2}}{I}\right) \\
& \times\left[K_{a r}\left(Z_{1 r}-Z_{2 r}\right)+C_{r}\left(\dot{Z}_{1 r}-\dot{Z}_{2 r}\right)+U_{p}\right] .
\end{aligned}
$$

By using (1) and (6), the semi-active air suspension for half-vehicle model can be constructed.

3.2. Air Spring Model. The type of air spring used in this study is the rolling lobe air spring, which is typically nonlinear. Yet most of the existing researches for semi-active suspension systems only use linear mechanical springs for their system models. Thus, a nonlinear spring model is used as one of original works in the modeling of the semi-active suspension system. Referring to Fox's description [35], the modeling of the rolling lobe air spring should be based on the effective volume, area, and other structural parameters. The variation of the interior air pressure and the cavity volume of air spring caused by the change of load should also be considered during the modeling process. Therefore, the rate of change of the effective area, as the most important characteristic, is derived first, and then the stiffness of the air spring system is derived accordingly. The whole air spring modeling procedure is conducted based on the laws of thermodynamics, and with the assumptions that the thermodynamic parameters do not vary with the position inside the air spring. 
The effective area of air spring is simply a linear variable with the change of the height of air spring. For any given moment, the effective area of air spring can be defined as

$$
A=A_{0}+\beta x,
$$

where $A_{0}$ is the initial effective area of air spring, $\beta$ is the change of the effective area with respect to $x$, and $x$ is the instantaneous height variation of air spring (i.e., $x=Z_{1 f}-$ $Z_{2 f}$ or $x=Z_{1 r}-Z_{2 r}$ ).

Apart from the effective area, the effective volume also changes at the same time. The effective volume of air spring can be defined as:

$$
V=V_{0}-\alpha x,
$$

where $V_{0}$ is the initial effective volume of air spring and $\alpha$ is the change of the effective volume with respect to $x$.

When the air spring is moving slowly, it is generally assumed that the interior gas of air spring is isothermal condition, so the interior pressure of the spring obeys the Boyle's law:

$$
\left(p+p_{a}\right) V=\left(p_{a}+p_{0}\right) V_{0},
$$

where $p$ is the air pressure of final state, $p_{a}$ is the standard atmospheric pressure, $p_{0}$ is the air pressure of initial state, $V$ is the final effective volume of air spring, and $V_{0}$ is the initial effective volume of air spring.

If the compression or expansion stroke is rapid enough, it can be regarded as an adiabatic process. Then, the air state can be defined as

$$
\left(p+p_{a}\right) V^{\gamma}=\left(p_{a}+p_{0}\right) V_{0}^{\gamma},
$$

where $\gamma$ is specific heat ratio.

However, in practice, the interior gas in air spring is neither isothermal process nor adiabatic process. Rather, it is a multivariable process between the isothermal and adiabatic processes. If the air is under the isothermal process, the stiffness of the air spring is small. If the air is under adiabatic process, the stiffness of the air spring is large. Therefore, the polytropic coefficient $\gamma$ is somewhere between the isothermal and adiabatic states. Since the current process tends to be an adiabatic process, a value around 1.3-1.4 is taken. Based on (10), the final interior air pressure of air spring in this study is defined as

$$
p=\left(p_{0}+p_{a}\right)\left(\frac{V_{0}}{V}\right)^{\gamma}-p_{a} .
$$

The elastic force of air spring can be calculated as

$$
F=p A .
$$

By substituting (11) into (12), the equation becomes

$$
F=\left[\left(p_{0}+p_{a}\right)\left(\frac{V_{0}}{V}\right)^{\gamma}-p_{a}\right] A .
$$

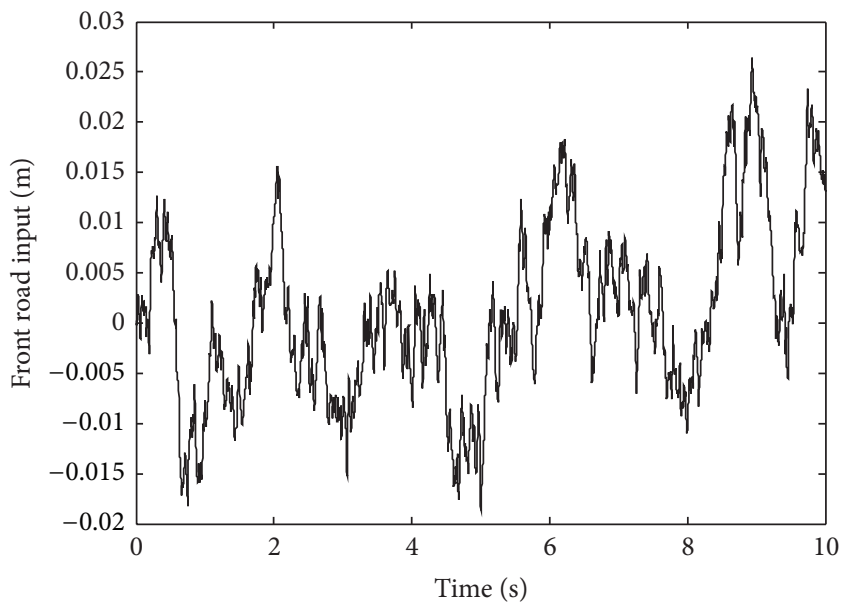

FIgURE 3: Road input of front wheel.

The effective area and the effective volume are functions of displacement, so the stiffness of air spring can be obtained with the derivative of displacement as follows:

$$
k=\frac{d F}{d x}=-A \gamma\left(p+p_{a}\right) \frac{1}{V} \frac{d V}{d x}+p \frac{d A}{d x} .
$$

The stiffness of air spring at standard height (when the displacement $x=0$ ) is

$$
k=\frac{d F}{d x}=-A \gamma \alpha\left(\frac{m_{2} g}{A_{0}}+P_{a}\right) \frac{1}{V}+\left.\frac{m_{2} g}{A_{0}} \frac{d A}{d x}\right|_{x=0} .
$$

\section{Road Input and Road Prediction Models}

4.1. Road Input Model. The function of the road input model is to provide the road information for the front wheel. To simulate the road roughness, a time domain displacement model is used in this study as the road input model, with the assumption that the input signal is band-limited white noise. The random road roughness (white noise) is used to represent the disturbance of road input. The standard mathematical model of a random excitation of road surface for single wheel with a constant vehicle speed $v$ is expressed as

$$
\dot{Z}_{0 f}+\mu \nu Z_{0 f}=\omega(t),
$$

where $\mu$ is the road spatial frequency and $\omega(t)$ is the white noise. In this study, the road spatial frequency and vehicle speed $v$ are defined as 0.1303 and $60 \mathrm{~km} / \mathrm{h}$, respectively. The corresponding time domain road profile is shown in Figure 3.

4.2. Road Prediction Model for Rear Wheel. The function of the road prediction model is to predict the road information for the rear wheel based on the road information sensed by the front wheel. In most of the previous studies, the road information for the rear wheel is assumed to have the same magnitude as that of the front wheel, but with different phases. Obviously, the vibration of the vehicle body is ignored because disturbance signals will be inevitably introduced 
during the prediction process. Therefore, to deal with this problem, the front wheel and the rear wheel of the vehicle should be considered separately, so a quarter vehicle model should be used as the base to create the road prediction model. Then, considering half of the free body diagram in Figure 2, the equations of motion for a front quarter vehicle can be obtained as follows:

$$
\begin{gathered}
m_{2 f} \ddot{Z}_{2 f}+C_{f}\left(\dot{Z}_{2 f}-\dot{Z}_{1 f}\right)+K_{a f}\left(Z_{2 f}-Z_{1 f}\right)=0, \\
m_{1 f} \ddot{Z}_{1 f}+C_{f}\left(\dot{Z}_{1 f}-\dot{Z}_{2 f}\right)+K_{a f}\left(Z_{1 f}-Z_{2 f}\right) \\
+K_{t f}\left(Z_{0 f}-Z_{1 f}\right)=0 .
\end{gathered}
$$

As mentioned in Section 1, the vertical acceleration of the unsprung mass is used instead of the vertical acceleration of the sprung mass in the road prediction procedure. Hence, the relationship between the road input and the vertical acceleration of the unsprung mass should be determined. The front unsprung mass acceleration is defined as

$$
X(s)=\ddot{Z}_{1 f},
$$

where $X(s)$ means the vertical acceleration of front axle.

By applying Laplace transform to (17) and (18) and combining them together, the relationship can first be obtained as the following transfer function:

$$
H(s)=\frac{Z_{0 r}(s)}{X(s)}=\frac{b_{3} s^{3}+b_{2} s^{2}+b_{1} s+b_{0}}{a_{4} s^{4}+a_{3} s^{3}+a_{2} s^{2}},
$$

where

$$
\begin{gathered}
a_{2}=K_{a f} K_{t f}, \\
a_{3}=C_{f} K_{a f}, \\
a_{4}=m_{2 f} K_{t f}, \\
b_{0}=K_{a f} K_{t f}, \\
b_{1}=C_{f} K_{t f}+m_{1 f} K_{a f}, \\
b_{2}=m_{2 f} K_{a f}+m_{2 f} K_{t f}+C_{f} m_{1 f}, \\
b_{3}=m_{1 f} m_{2 f}+C_{f} m_{2 f} .
\end{gathered}
$$

With the constructed half-vehicle model in Section 3 and (20), the road information for the rear wheel, $Z_{0 r}$, can be predicted for any given $X(s)$.

\section{Design of Wavelet Fuzzy-Wheelbase Preview Controller}

5.1. Wavelet Denoising Filter. There are three types of wavelet transform, which are continuous wavelet transform (CWT), wavelet packet transform (WPT), and discrete wavelet transform (DWT). The CWT is mainly used for signal analysis, the WPT is usually used for signal decomposition while the DWT is often used for data preconditioning and processing. The role of the wavelet denoising filter in this study is to suppress the signal disturbance before it is being entered into the rear half-vehicle suspension, so the DWT is used in this study and it can be represented as

$$
\mathbf{w}=\mathbf{W} f
$$

where $\mathbf{w}$ is a vector containing wavelet transform coefficients, $\mathbf{W}$ is the matrix of the wavelet filter coefficients, and $f$ is the discrete signal. Each $\mathbf{W}$ is a set of basic vectors, and these vectors can be derived from a mother wavelet by translation and dilation; the mother wavelet $\psi$ is

$$
\psi_{a, b}(t)=\frac{1}{\sqrt{|a|}} \psi\left(\frac{t-b}{a}\right),
$$

where $a$ is a scaling variable and $b$ is a translation variable.

The main steps of wavelet denoising are signal decomposition, signal thresholding (used for elimination of small coefficients), and signal reconstruction. Regarding the decomposition and reconstruction of the signal, a dyadic dilations and translation mother wavelet method proposed by Mallat [36] is used:

$$
\psi_{(s, l)}=2^{-s / 2} \psi\left(2^{-s} t-l\right),
$$

where $s$ is the scaling variable and $l$ is the location index. Then, by constraining the $\psi, s$, and $l$, an orthogonal decomposition can be achieved. In this study, the composition level is 3 and the threshold method is Haar. Finally, the signal construction in the case of orthogonal $W$ can be described with the following equation and the filtered signal $f$ can be obtained:

$$
f=\mathbf{W}^{t} \mathbf{w} \text {. }
$$

5.2. Fuzzy Controller. In classical semi-active vehicle suspension system, the state feedback of disturbance signals (SFDS), which are important for the fuzzy controller, cannot be measured [37]. While the fuzzy controller in this study is combined with the preview model, by which the SFDS of the vehicle can be effectively introduced, the absence of the SFDS is effectively avoided.

The design of the fuzzy controller is as follows: the tire deflection " $E$ " and its derivation " $E C$ " are the two input variables, while the command signal for the variable damper " $U$ " is corresponding output of the controller. The value of $U$ can be viewed as the damping force in this study, The shape of membership function for all the three variables is the Gaussian function, in which six linguistic variables are defined, including Negative Big "NB", Negative Medium "NM", Negative Small "NS," Zero “Z," Positive Small "PS", Positive Medium "PM", and Positive Big "PB." The type of fuzzy inference system is Mamdani, and the fuzzy rules are given in Table 1.

5.3. Preview Model. In the preview control model, firstly, a nominal quarter vehicle model is used to obtain the response of vehicle state, and the transfer function is

$$
G_{n}(s)=\frac{Z(s)}{U_{r}(s)},
$$


TABLE 1: Rules of the fuzzy controller.

\begin{tabular}{|c|c|c|c|c|c|c|c|c|}
\hline & \multirow[t]{2}{*}{$U$} & \multicolumn{7}{|c|}{$E C$} \\
\hline & & $\mathrm{NB}$ & NM & NS & $Z$ & PS & $\mathrm{PM}$ & PB \\
\hline \multirow{7}{*}{$E$} & NB & $\mathrm{PB}$ & $\mathrm{PB}$ & $\mathrm{PM}$ & $\mathrm{PM}$ & PS & $Z$ & $Z$ \\
\hline & NM & $\mathrm{PB}$ & $\mathrm{PM}$ & $\mathrm{PM}$ & $\mathrm{PM}$ & PS & $Z$ & $Z$ \\
\hline & NS & PS & PS & PS & PS & PS & NS & NS \\
\hline & $Z$ & PS & PS & $Z$ & $Z$ & NS & NM & NM \\
\hline & PS & PS & $Z$ & NS & NS & NS & NS & $\mathrm{NM}$ \\
\hline & PM & PS & $Z$ & NS & NM & $\mathrm{NM}$ & $\mathrm{NM}$ & NB \\
\hline & PB & $Z$ & NS & NS & NM & NM & $\mathrm{NB}$ & NB \\
\hline
\end{tabular}

where $Z(s)$ is the output in $s$-domain (i.e., the sprung mass acceleration $\left.\ddot{Z}_{2 r}\right)$ and $U_{r}(s)$ is the real input in $s$-domain from the load cell (i.e., the damping force for rear suspension). In other words, the damping force is first provided to the nominal quarter vehicle model and the corresponding sprung mass acceleration of rear quarter vehicle can be predicted. Then, the sprung mass acceleration computed from the nominal model is used to calculate the preview control damping force $U_{p}$ with the following transfer function:

$$
\begin{aligned}
G_{n}^{-1}(s)= & \frac{U_{p}(s)}{\ddot{Z}_{2 r}(s)} \\
= & \left(m_{2 r} m_{1 r} s^{4}+\left(m_{2 r}+m_{1 r}\right) C_{r} s^{3}\right. \\
& \quad+\left(m_{1 r} K_{a r}+m_{2 r} K_{a r}+m_{2 r} K_{t r}\right) s^{2} \\
& \left.\quad+C_{r} K_{t r} s+K_{t r} K_{a r}\right) \times\left(m_{1 r} s^{4}+K_{t r} s^{2}\right)^{-1} .
\end{aligned}
$$

\section{Results and Analysis}

In order to show the performance of the proposed SFPW on semi-active air suspension, simulations under heavyduty vehicle environment were carried out based on the models created in the previous sections and parameters in Table 2. The simulations were also conducted using SFP, SF, and traditional APP, so that comparison can be made and the effectiveness of the proposed SFPW can be realized. In addition, the modeling of the fully active suspension system, which is used for the APP in comparison, has almost the same modeling process with the semi-active one, except the controller and generation of the active force. Moreover, five characteristics of the suspension are used to represent the performance of the suspension. They are the sprung mass acceleration, the tire deflection, the suspension deflection, the pitch, and the tire load.

Figures 4 and 5 show the sprung mass acceleration and the tire deflection, respectively. Normally, the smaller these values, the better the ride comfort and road holding performance. Therefore, it can be seen that the proposed SFPW could provide the best ride comfort and ride holding performance among all the other methods, regardless of the front or rear suspensions.

Figure 6 demonstrates the suspension deflection of the front and rear quarter vehicles. This time, the performance of
TABLE 2: Input parameters of half-vehicle model.

\begin{tabular}{lcc}
\hline Parameter & Unit & Value \\
\hline$C_{f}$ & $\mathrm{~N} \cdot \mathrm{m} / \mathrm{s}$ & 15000 \\
$C_{r}$ & $\mathrm{~N} \cdot \mathrm{m} / \mathrm{s}$ & 15000 \\
$I$ & $\mathrm{~kg} \cdot \mathrm{m}^{2}$ & 73603 \\
$K_{t f}$ & $\mathrm{kN} / \mathrm{m}$ & 592000 \\
$K_{t r}$ & $\mathrm{kN} / \mathrm{m}$ & 3000000 \\
$L_{a}$ & $\mathrm{~m}$ & 1.113 \\
$L_{b}$ & $\mathrm{~m}$ & 3.2 \\
$M$ & $\mathrm{Kg}$ & 4174 \\
$m_{1 f}$ & $\mathrm{~kg}$ & 145 \\
$m_{1 r}$ & $\mathrm{~kg}$ & 312 \\
$m_{2 f}$ & $\mathrm{~kg}$ & 917 \\
$m_{2 r}$ & $\mathrm{~kg}$ & 3257 \\
$A_{0 f^{*}}$ & $\mathrm{~m}^{2}$ & 0.0381 \\
$A_{0 r^{*}}$ & $\mathrm{~m}^{2}$ & 0.0706 \\
$\alpha_{f^{*}}$ & $/$ & 0.059 \\
$\alpha_{r^{*}}$ & $/$ & 0.0827 \\
$\beta_{f^{*}}$ & $/$ & 0.0186 \\
$\beta_{r^{*}}$ & $/$ & 0.0207 \\
$V_{0 f^{*}}$ & $/$ & 0.0078 \\
$V_{0 r^{*}}$ & $\mathrm{~m}^{3}$ & 0.0233 \\
$p_{0 f^{*}}$ & $\mathrm{~m}^{3}$ & 0.382 \\
$p_{0 r^{*}}$ & $\mathrm{Mpa}$ \\
$p_{a}$ & $\mathrm{Mp}$ & 0.3 \\
$\gamma$ & $\mathrm{Mpa}$ & 0.1 \\
$(\mathrm{i}) f * 33$ \\
\hline
\end{tabular}

*(i) $f$ stands for the front $1 / 4$ vehicle model.

(ii) $r$ stands for the rear $1 / 4$ vehicle model.

APP is superior to the other three control methods. Although SPFW is the worst for the suspension deflection of the front quarter vehicle, it exhibits a better suspension deflection than SF for the rear quarter vehicle, meaning that the SPFW is still comparable in this category.

Figure 7 illustrates the pitch and pitch angle acceleration of the half-vehicle model. A good suspension system should be able to minimize the pitch motion and pitch angle acceleration. As it can be learnt from Figure 7, the APP has a better performance in terms of pitch angle while the SFPW behaves noticeably the best in the pitch angle acceleration in all the control methods.

Figure 8 shows the tire load performance (i.e., road friendliness) of the front and rear wheels. Road friendliness refers to the extent of damage exerted on the road by the vehicle, this performance is particularly important for heavyduty vehicles, and this damage is mainly decided by the dynamic tire load [38]. From Figure 8(a), SFPW performs almost the same as SF for the tire load of front suspension, but from Figure 8(b), it can be learnt that SFPW outperforms the others for the rear suspension. Therefore, the road damage can be minimized with the SFPW. Besides, it can be observed from Figures 4 to 8 that SFPW has smoother results than SFP, indicating that the addition of wavelet filter can significantly reduce the noise in the sensor signals. 

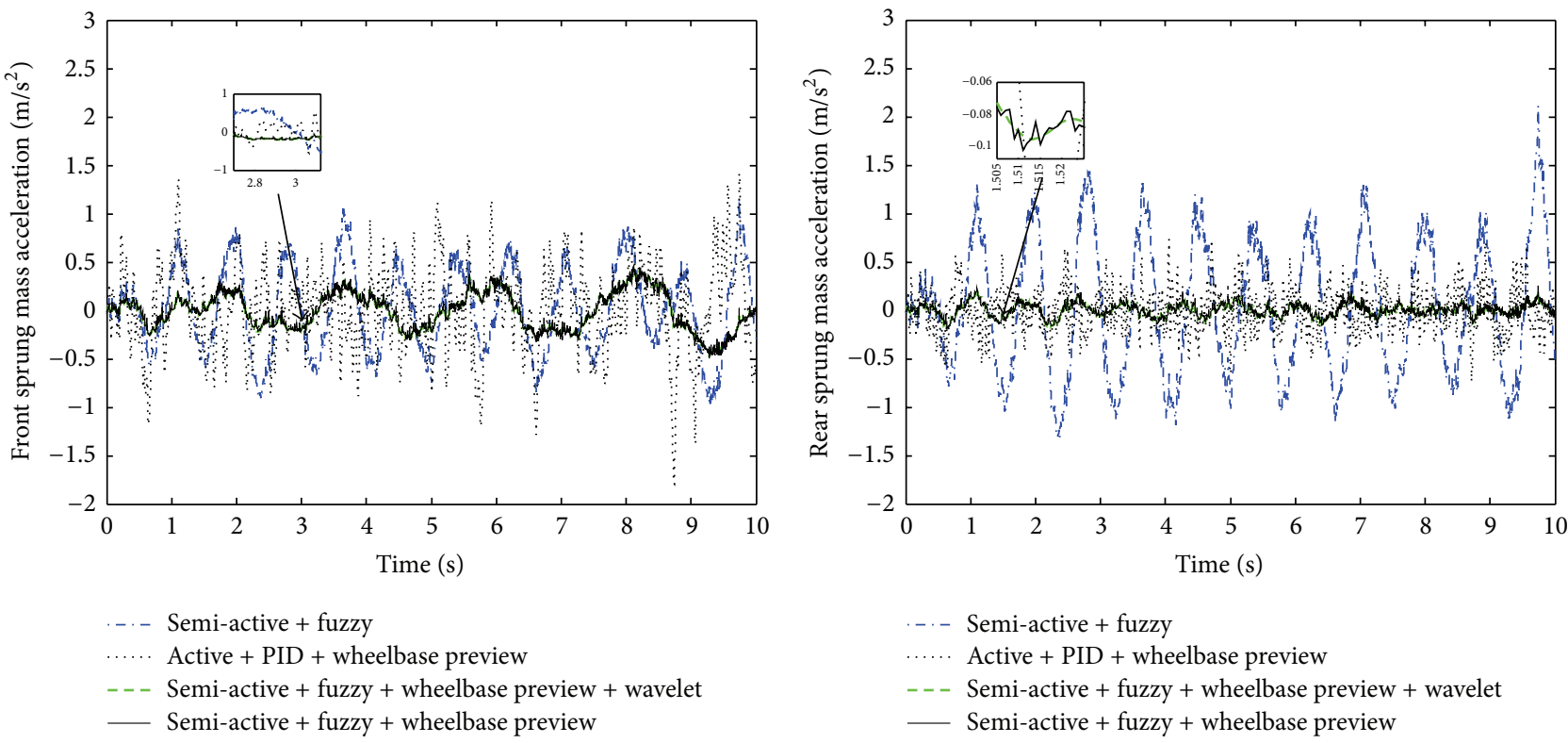

(a) Front sprung mass acceleration

(b) Rear sprung mass acceleration

FIGURE 4: Comparison of sprung mass acceleration.

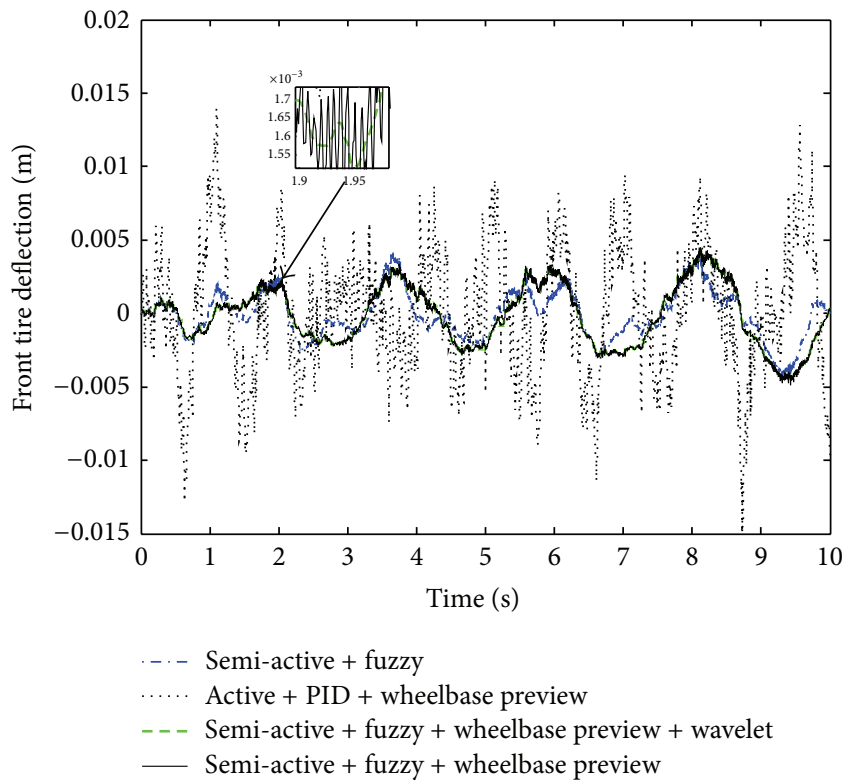

(a) Front tire deflection

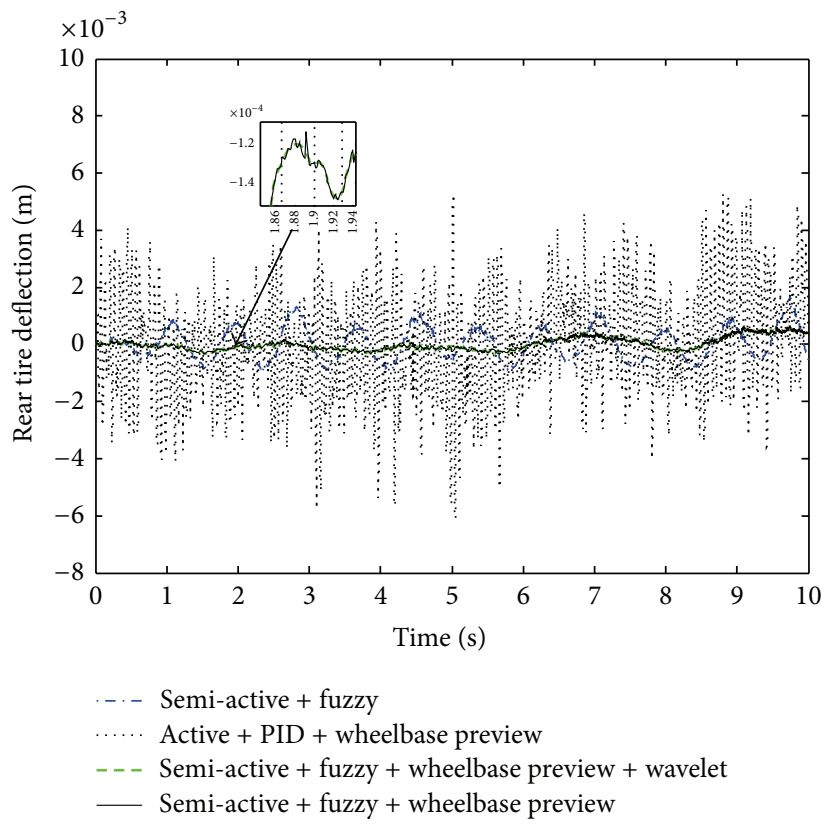

(b) Rear tire deflection

FIGURE 5: Comparison of tire deflection.

Other than comparing the five performance indexes individually, the overall performance evaluation of the controllers is also desired. However, many performance indexes are somewhat in conflict with each other and the direct comparison is difficult [39]. Hence, an overall fitness is used as the evaluation method, which is similar to the fitness function proposed by [40]. The basic idea is to sum up various normalized performance indexes with different user-defined weights. In general, the suspension on a vehicle typically has the following basic tasks, which are providing ride comfort, road holding, competent handling, and the support of the vehicle static weight. However, the handling capacity cannot be reasonably judged in a half-vehicle model, and the ride quality can be quantified by the sprung mass acceleration, the road holding capacity can be represented by the tire deflection, and the support of static weight can be specified 

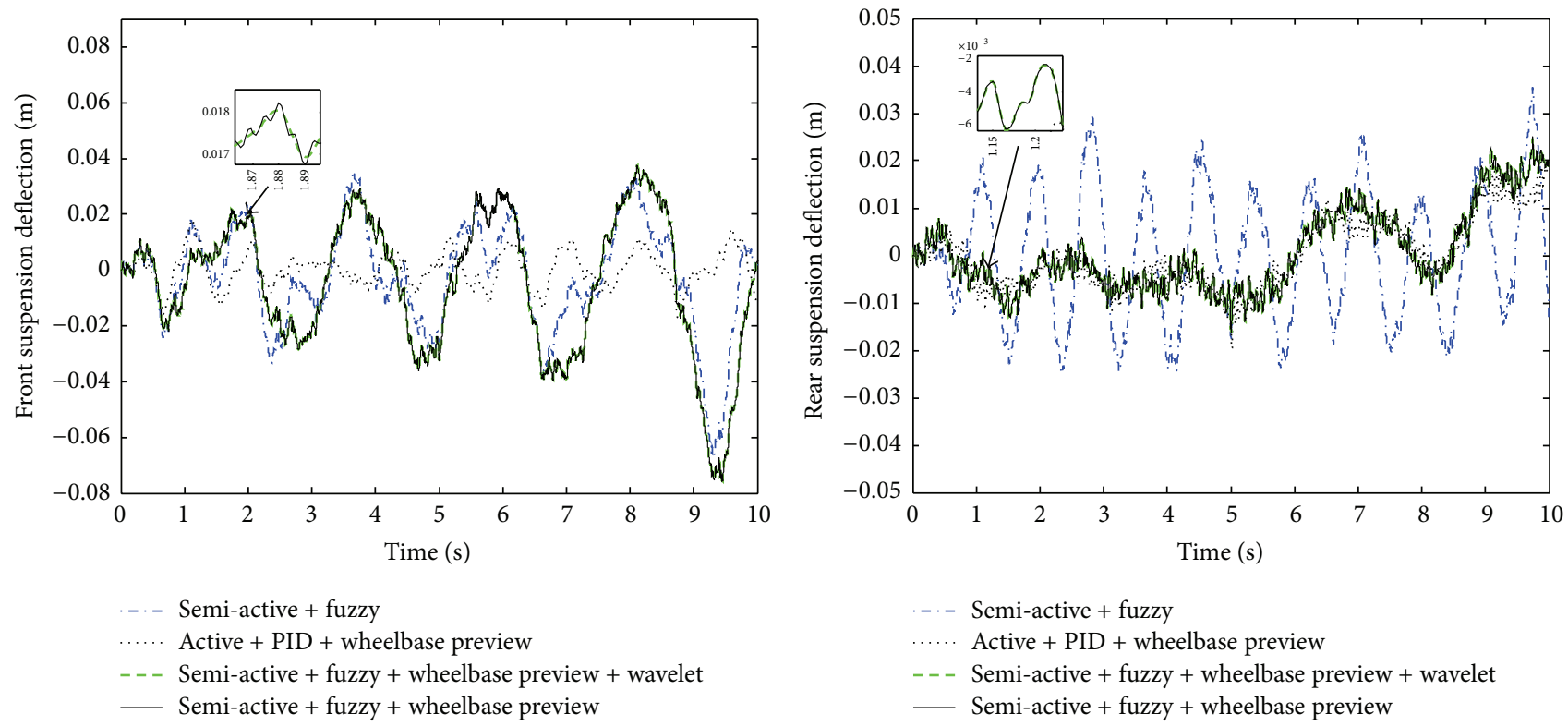

... Semi-active + fuzzy

… Active + PID + wheelbase preview

- - - Semi-active + fuzzy + wheelbase preview + wavelet

— Semi-active + fuzzy + wheelbase preview

(a) Front suspension deflection

(b) Rear suspension deflection

FIGURE 6: Comparison of suspension deflection.

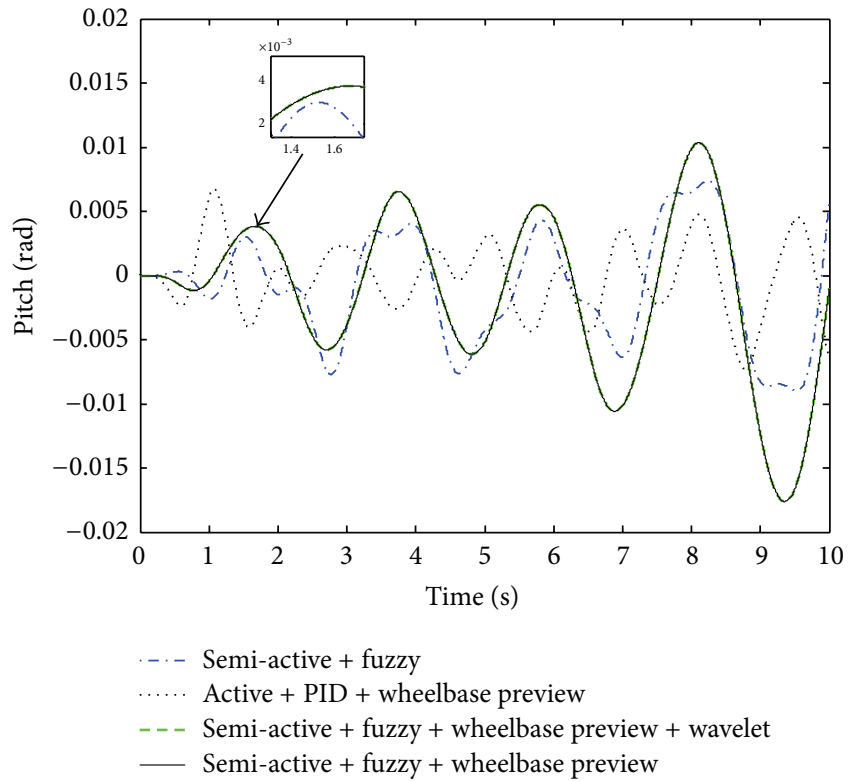

(a) Pitch

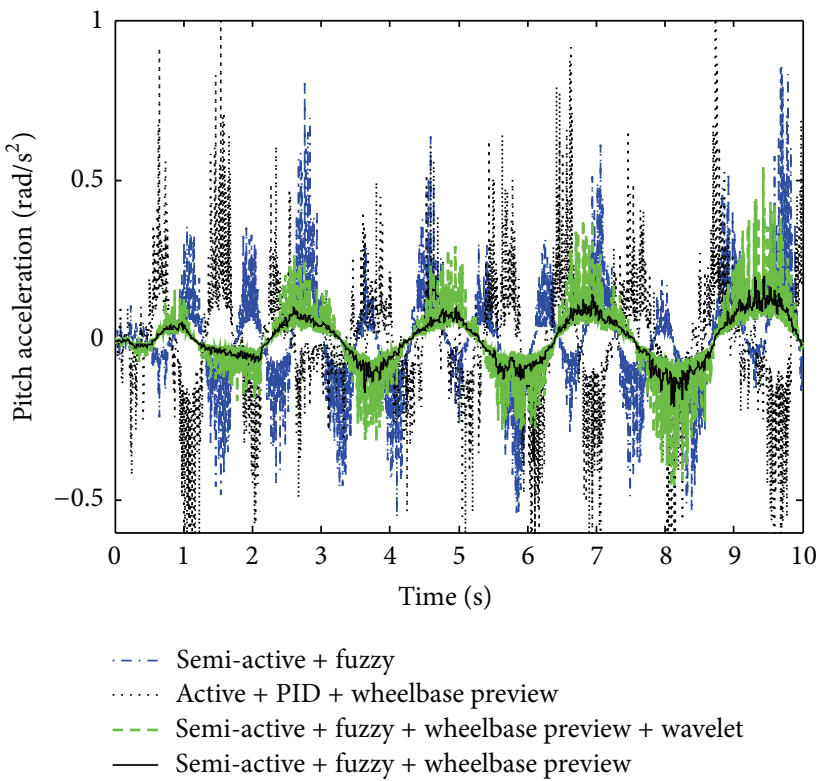

(b) Pitch acceleration

FIgURE 7: Comparison of pitch and pitch acceleration.

by the suspension deflection [1]. Thus, in this study, only three objectives were considered instead of five, which are the sprung mass acceleration, the tire deflection, and the suspension deflection.

Regarding the root mean square (RMS) rear suspension fitness $\left(\eta_{r}\right)$, RMS tire deflection $\left(\eta_{r t}\right)$, RMS sprung mass acceleration $\left(\eta_{r a}\right)$, and RMS suspension deflection $\left(\eta_{r s}\right)$ are ranked in the order of importance, and the corresponding weights $w_{r t}, w_{r a}$, and $w_{r s}$ were set as $0.4,0.35$, and 0.25 , respectively. For the RMS front suspension fitness $\left(\eta_{f}\right)$, the weights were in the order of RMS sprung mass acceleration $\left(\eta_{f a}\right)$, tire deflection $\left(\eta_{f t}\right)$, and suspension deflection $\left(\eta_{f s}\right)$, and the corresponding weights $w_{f a}, w_{f t}$, and $w_{f s}$ are $0.45,0.3$, and 0.25 , respectively. The weights of the front $w_{f}$ and rear $w_{r}$ 


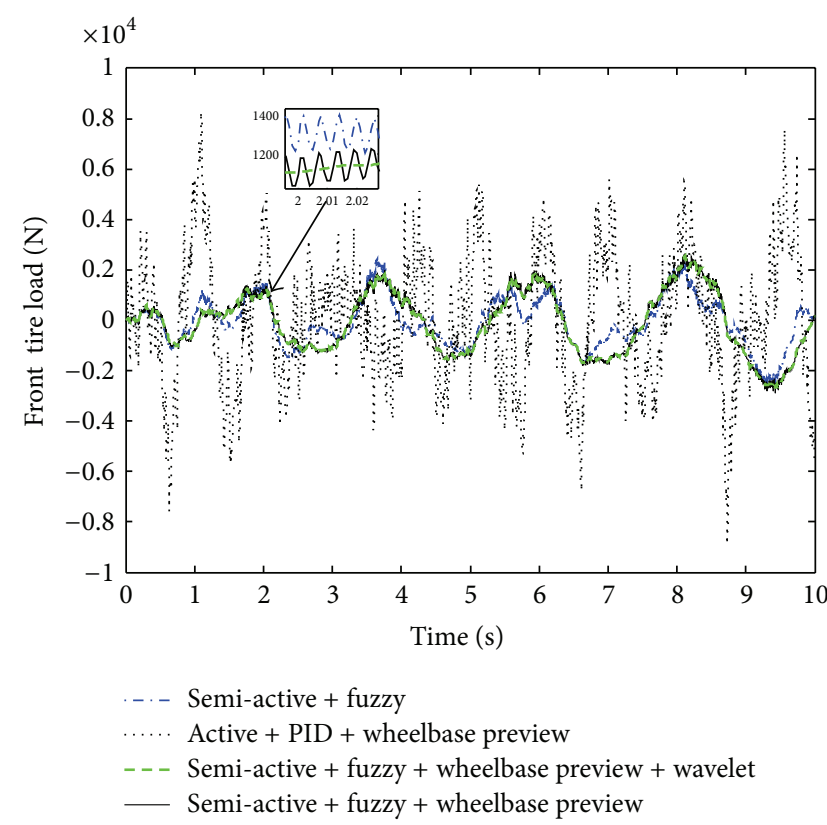

(a) Front tire load

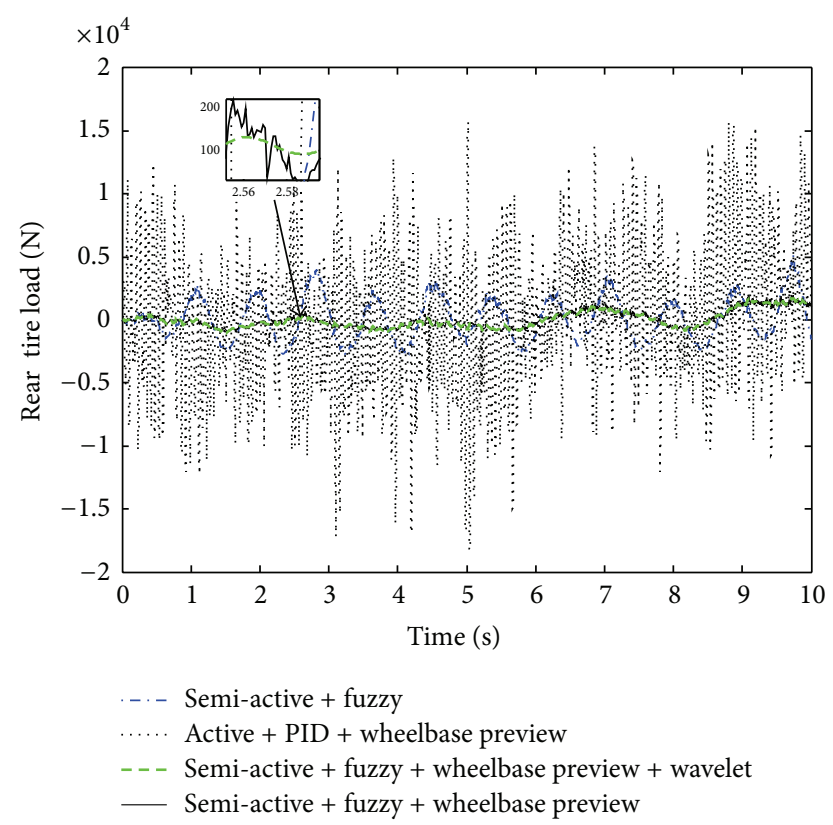

(b) Rear tire load

FIGURE 8: Comparison of tire load.

TABLE 3: Control performance with different control strategies.

\begin{tabular}{lccccc}
\hline Performance & SF $^{*}$ & APP & SFP $^{*}$ & SFPW $^{*}$ & SFPW versus APP \\
\hline RMS front sprung mass acceleration & 0.4484 & 0.4477 & 0.1943 & $\mathbf{0 . 1 9 3 9}$ & $56.69 \%$ \\
RMS rear sprung mass acceleration & 0.7012 & 0.2217 & 0.0665 & $\mathbf{0 . 0 6 0 7}$ & $72.62 \%$ \\
RMS front tire deflection & $\mathbf{0 . 0 0 1 6}$ & 0.0044 & 0.0020 & 0.0020 & $54.55 \%$ \\
RMS rear tire deflection & 0.0005583 & 0.0018 & 0.0002192 & $\mathbf{0 . 0 0 0 2 1 9 0}$ & $87.83 \%$ \\
RMS front suspension deflection & 0.0194 & $\mathbf{0 . 0 0 6 4}$ & 0.0258 & 0.0250 & $-290.62 \%$ \\
RMS rear suspension deflection & 0.0136 & $\mathbf{0 . 0 0 7 4}$ & 0.0088 & 0.0085 & $-14.86 \%$ \\
$\eta_{f}$ & 5151.5871 & $\mathbf{5 1 2 2 . 4 5 6 0}$ & 5321.2273 & 5272.9123 & $-2.94 \%$ \\
$\eta_{r}$ & 5125.8603 & 4398.9401 & 3882.3721 & $\mathbf{3 7 4 8 . 8 6 8 3}$ & $14.78 \%$ \\
$\eta_{c}$ & 5136.1510 & 4688.3465 & 4457.9142 & $\mathbf{4 3 5 8 . 4 8 5 9}$ & $7.04 \%$ \\
\hline
\end{tabular}

*(i) SF: semi-active air suspension with fuzzy control.

(ii) APP: active suspension with PID-wheelbase preview control.

(iii) SFP: semi-active suspension with fuzzy-wheelbase preview control.

(iv) SFPW: semi-active suspension with fuzzy-wheelbase preview control and wavelet filter.

suspension are set as 0.4 and 0.6 , respectively. The equations of the overall fitness function of the suspension performance $\eta_{c}$ are shown as follows:

$$
\begin{gathered}
\eta_{c}=w_{f} \eta_{f}+w_{r} \eta_{r} \\
\eta_{f}=w_{f a} N\left(\eta_{f a}\right)+w_{f t} N\left(\eta_{f t}\right)+w_{f s}\left(\eta_{f s}\right), \\
\eta_{r}=w_{r t}\left(\eta_{r t}\right)+w_{r a}\left(\eta_{r a}\right)+w_{r s}\left(\eta_{r s}\right),
\end{gathered}
$$

where the $N(\bullet)$ is the normalization function which transforms the objective component value to the range $[0,1]$ so as to ensure each component has the same contribution to the fitness function. The general form of the normalization function is given in

$$
v_{t}^{*}=\frac{\left(v_{t}-v_{\min }\right)}{\left(v_{\max }-v_{\min }\right)},
$$

where $v_{t}^{*}$ is the normalized performance index and $v_{\max }$ and $v_{\text {min }}$ are the upper limit and lower limit of the performance index before normalization.

With the above method, the RMS values of the individual performance index and the overall fitness from the simulation results are given in Table 3 . It is shown that both the sprung mass acceleration and rear tire deflection of the half vehicle controlled by SFPW are improved remarkablly in contrast with the other three methods. Compared with the APP method, the SFPW method has the following improvements. 
(1) The RMS values of front and rear sprung mass accelerations are reduced by $56.69 \%$ and $72.62 \%$, respectively.

(2) The RMS values of the front and rear tire deflections are reduced by $54.55 \%$ and $87.73 \%$, respectively.

(3) An apparent situation is that the RMS values of the front and rear suspension deflections by SFPW method are increased, respectively, by $290.62 \%$ and $14.86 \%$, which are obviously worse than that of the APP method.

(4) The fitness value of the front suspension is decreased by $2.94 \%$, while the fitness of the rear suspension is increased by $14.78 \%$, and the comprehensive performance is improved by $7.04 \%$.

\section{Conclusion}

In this paper, a new fuzzy-wheelbase preview controller integrated with wavelet filter has been developed for a semiactive air suspension. The wavelet filter is originally used for suppressing the noise of measured signals. Evaluation results show that the controller with wavelet filter can output smooth signals under sudden change of the frequency, which can make the system stable. Moreover, this paper also originally applies the idea of placing the acceleration sensors on the front axle to reasonably reflect the actual road roughness. A fitness function is constructed to formulate the weights of comprehensive performance indexes. The simulation results show that the integrated fuzzy-wheelbase preview controller of semi-active suspension can effectively improve the ride quality and road holding capacity. It is also noted that even though the rear suspension carries the main load in the heavy-duty vehicle, the road friendliness can still be improved significantly. Overall speaking, the comprehensive performance of the vehicle is greatly improved by the proposed controller.

\section{Nomenclature}

$L_{a}$ : Longitudinal distance from front wheel center to center of gravity of vehicle

$L_{b}$ : Longitudinal distance from rear wheel center to center of gravity of vehicle

$C_{f}$ : Damping ratio of front suspension

$C_{r}$ : Damping ratio of rear suspension

$g$ : Acceleration of gravity

I: $\quad$ Total moment of inertia

$K_{a f}$ : Stiffness of front suspension

$K_{a r}$ : Stiffness of rear suspension

$K_{t f}$ : Stiffness of front tire

$K_{t r}$ : Stiffness of rear tire

$M$ : Total sprung mass

$m_{1 f}$ : Front unsprung mass

$m_{1 r}$ : Rear unsprung mass

$m_{2}$ : Sprung mass of quarter vehicle

$m_{2 f}$ : Front sprung mass $m_{2 r}$ : Rear sprung mass

$v$ : Speed of vehicle

$Z_{0 f}$ : Road profile of front wheel

$Z_{0 r}$ : Road profile of rear wheel

$Z_{1 f}$ : Vertical displacement of front unsprung mass

$Z_{1 r}$ : Vertical displacement of rear unsprung mass

$Z_{2 f}$ : Vertical displacement of front sprung mass

$Z_{2 r}$ : Vertical displacement of rear sprung mass

$Z_{c}$ : Vertical displacement of total sprung mass

$\theta: \quad$ Pitch angle.

\section{Acknowledgment}

This work has been supported by the following multi-year research funds from University of Macau: MYRG042(Y2-L1)FST12-XZC, MYRG077(Y1-L2)-FST13-WPK, and MYRG081 (Y2-L2)-FST12-WPK.

\section{References}

[1] R. Rajamani, Vehicle Dynamics and Control, 2nd edition, 2012.

[2] S. M. Savaresi, V. C. Poussot, and C. Spelta, Semiactive Suspension Control Design for Vehicles, Elsevier, 2010.

[3] L. BalaMurugan and J. Jancirani, "An investigation on semiactive suspension damper and control strategies for vehicle ride comfort and road holding," Proceedings of the Institution of Mechanical Engineers I, vol. 226, no. 8, pp. 1119-1129, 2012.

[4] M. J. Crosby, R. A. Harwood, and D. Karnopp, "Vibration control using semi-active force generators," Lord Library of Technical Articles, vol. 7004, pp. 619-626, 1973.

[5] X. B. Song, M. Ahmadian, and S. Southward, "Analysis and strategy for superharmonics with semiactive suspension control systems," Journal of Dynamic Systems, Measurement and Control, vol. 129, no. 6, pp. 795-803, 2007.

[6] K. S. Hong, H. C. Sohn, and J. K. Hedrick, "Modified skyhook control of semi-active suspensions: a new model, gain scheduling, and hardware-in-the-loop tuning," Journal of Dynamic Systems, Measurement and Control, vol. 124, no. 1, pp. 158-167, 2002.

[7] D. Sammier, O. Sename, and L. Dugard, "Skyhook and Ho control of semi-active suspensions: some practical aspects," Vehicle System Dynamics, vol. 39, no. 4, pp. 279-308, 2003.

[8] H. C. Sohn, K. S. Hong, and J. K. Hedrick, "Semi-active control of the Macpherson suspension system: hardware-in-the-loop simulations," in Proceedings of IEEE International Conference on Control Applications, pp. 982-987, 2000.

[9] M. Ieluzzi, P. Turco, and M. Montiglio, "Development of a heavy truck semi-active suspension control," Control Engineering Practice, vol. 14, no. 3, pp. 305-312, 2006.

[10] S. M. Savaresi, E. Silani, and S. Bittanti, "Acceleration-DrivenDamper (ADD): an optimal control algorithm for comfortoriented semiactive suspensions," Journal of Dynamic Systems, Measurement and Control, vol. 127, no. 2, pp. 218-229, 2005. 
[11] S. M. Savaresi and C. Spelta, "A single-sensor control strategy for semi-active suspensions," IEEE Transactions on Control Systems Technology, vol. 17, no. 1, pp. 143-152, 2009.

[12] H. Bolandhemmat, C. M. Clark, and F. Golnaraghi, "Development of a systematic and practical methodology for the design of vehicles semi-active suspension control system," Vehicle System Dynamics, vol. 48, no. 5, pp. 567-585, 2010.

[13] R. Morselli and R. Zanasi, "Control of port Hamiltonian systems by dissipative devices and its application to improve the semiactive suspension behaviour," Mechatronics, vol. 18, no. 7, pp. 364-369, 2008.

[14] M. Valasek and W. Kortum, "Road-friendly trucks," Structural Dynamics, vol. 1-2, pp. 855-860, 1999.

[15] J. Koo, M. Ahmadian, M. Setareh, and T. M. Murray, "In search of suitable control methods for semi-active tuned vibration absorbers," Journal of Vibration and Control, vol. 10, no. 2, pp. 163-174, 2004.

[16] N. Giorgetti, A. Bemporad, H. E. Tseng, and D. Hrovat, "Hybrid model predictive control application towards optimal semiactive suspension," International Journal of Control, vol. 79, no. 5, pp. 521-533, 2006.

[17] M. Canale, M. Milanese, and C. Novara, "Semi-active suspension control using "fast" model-predictive techniques," IEEE Transactions on Control Systems Technology, vol. 14, no. 6, pp. 1034-1046, 2006.

[18] X. M. Dong, M. Yu, C. R. Liao, and W. M. Chen, "Comparative research on semi-active control strategies for magnetorheological suspension," Nonlinear Dynamics, vol. 59, no. 3, pp. 433-453, 2010.

[19] M. Yu, X. M. Dong, S. B. Choi, and C. R. Liao, "Human simulated intelligent control of vehicle suspension system with MR dampers," Journal of Sound and Vibration, vol. 319, no. 3-5, pp. 753-767, 2009.

[20] T. Hashiyama, T. Furuhashi, and Y. Uchikawa, "Study on finding fuzzy rules for semi-active suspension controllers with genetic algorithm," in Proceedings of IEEE International Conference on Evolutionary Computation, vol. 1-2, pp. 279-282, December 1995.

[21] T. Yoshimura, K. Nakaminami, and J. Hino, "A semi-active suspension with dynamic absorbers of ground vehicles using fuzzy reasoning," International Journal of Vehicle Design, vol. 18, no. 1, pp. 19-34, 1997.

[22] N. Eslaminasab, M. Biglarbegian, W. W. Melek, and M. F. Golnaraghi, "A neural network based fuzzy control approach to improve ride comfort and road handling of heavy vehicles using semi-active dampers," International Journal of Heavy Vehicle Systems, vol. 14, no. 2, pp. 135-157, 2007.

[23] E. K. Bender, "Optimum linear preview control with application to vehicle suspension," Journal of Basic Engineering, vol. 100, pp. 213-221, 1968.

[24] Z. C. Xie, P. K. Wong, X. Z. Huang, and H. C. Wong, "Design of an active vehicle suspension based on an enhanced PID control with wheelbase preview and tuning using genetic algorithm," Journal of the Chinese Society of Mechanical Engineers, vol. 33, pp. 103-112, 2012.

[25] P. K. Wong, S. J. Huang, T. Xu, H. C. Wong, and Z. C. Xie, "Design of a new suspension system controlled by fuzzy-PID with wheelbase preview," Advanced Mechanical Engineering II, vol. 192, pp. 106-110, 2012.

[26] P. K. Wong, Z. C. Xie, H. C. Wong, and X. Z. Huang, "Design of a fuzzy preview active suspension system for automobiles," in Proceedings of the International Conference on System Science and Engineering (ICSSE '11), pp. 525-529, June 2011.

[27] M. M. ElMadany, "Control and evaluation of slow-active suspensions with preview for a full car," Mathematical Problems in Engineering, vol. 2012, Article ID 375080, 19 pages, 2012.

[28] A. Hac, "Optimal linear preview control of active vehicle suspension," Vehicle System Dynamics, vol. 21, no. 3, pp. 167-195, 1992.

[29] M. M. Elmadany, Z. Abduljabbar, and M. Foda, "Optimal preview control of active suspensions with integral constraint," Journal of Vibration and Control, vol. 9, no. 12, pp. 1377-1400, 2003.

[30] F. Richter, C. Sourkounis, and N. Bingchang, "Prediction of stochastically fluctuating values using the example of road surface roughness," in Procedings of the 17th Mediterranean Conference on Control and Automation, pp. 1009-1013, 2009.

[31] A. Grossmann and J. Morlet, "Decomposition of hardy functions into square integrable wavelets of constant shape," SIAM Journal on Mathematical Analysis, vol. 15, pp. 723-736, 1984.

[32] C. M. Vong and P. K. Wong, "Engine ignition signal diagnosis with Wavelet Packet Transform and Multi-class Least Squares Support Vector Machines," Expert Systems with Applications, vol. 38, no. 7, pp. 8563-8570, 2011.

[33] B. S. Wu and C. Z. Cai, "Wavelet denoising and its implementation in LabVIEW," in Proceedings of the 2nd International Congress on Image and Signal Processing (CISP '09), vol. 1-9, pp. 400-403, October 2009.

[34] D. P. Cao, S. Rakheja, and C. Y. Su, "Heavy vehicle pitch dynamics and suspension tuning. Part I: unconnected suspension," Vehicle System Dynamics, vol. 46, no. 10, pp. 931-953, 2008.

[35] M. N. Fox, R. L. Roebuck, and D. Cebon, "Modelling rollinglobe air springs," International Journal of Heavy Vehicle Systems, vol. 14, no. 3, pp. 254-270, 2007.

[36] S. G. Mallat, “Theory for multiresolution signal decomposition: the wavelet representation," IEEE Transactions on Pattern Analysis and Machine Intelligence, vol. 11, no. 7, pp. 674-693, 1989.

[37] D. Krokavec and A. Filasova, "Optimal fuzzy control for a class of nonlinear systems," Mathematical Problems in Engineering, vol. 2012, Article ID 481942, 29 pages, 2012.

[38] D. J. Cole and D. Cebon, “Truck suspension design to minimize road damage," Proceedings of the Institution of Mechanical Engineers D, vol. 210, no. 2, pp. 95-107, 1996.

[39] L. Chai and T. Sun, "The design of LQG controller for active suspension based on analytic hierarchy process," Mathematical Problems in Engineering, vol. 2010, Article ID 701951, 19 pages, 2010.

[40] P. K. Wong, L. M. Tam, and L. Ke, "Automotive engine power performance tuning under numerical and nominal data," Control Engineering Practice, vol. 20, no. 3, pp. 300-314, 2012. 


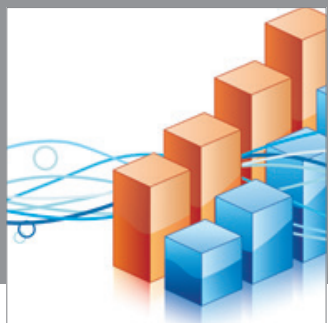

Advances in

Operations Research

mansans

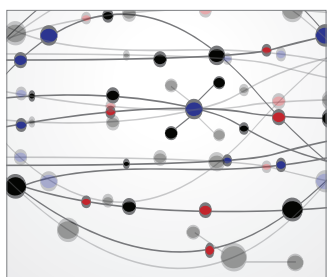

The Scientific World Journal
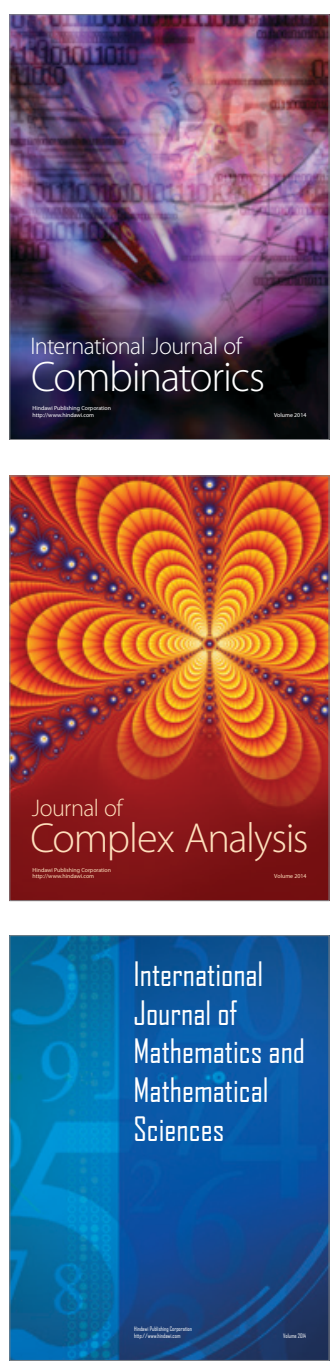
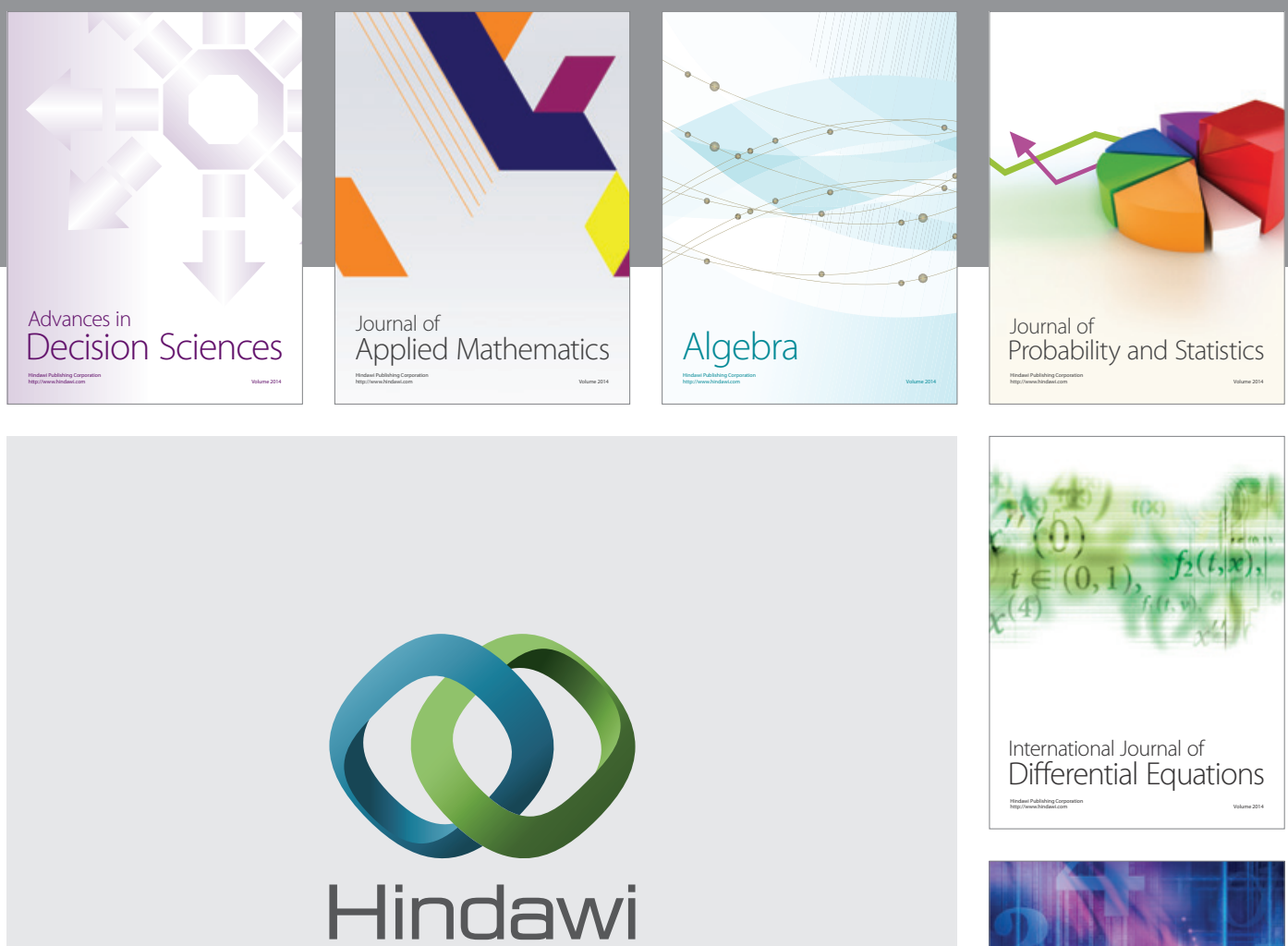

Submit your manuscripts at http://www.hindawi.com
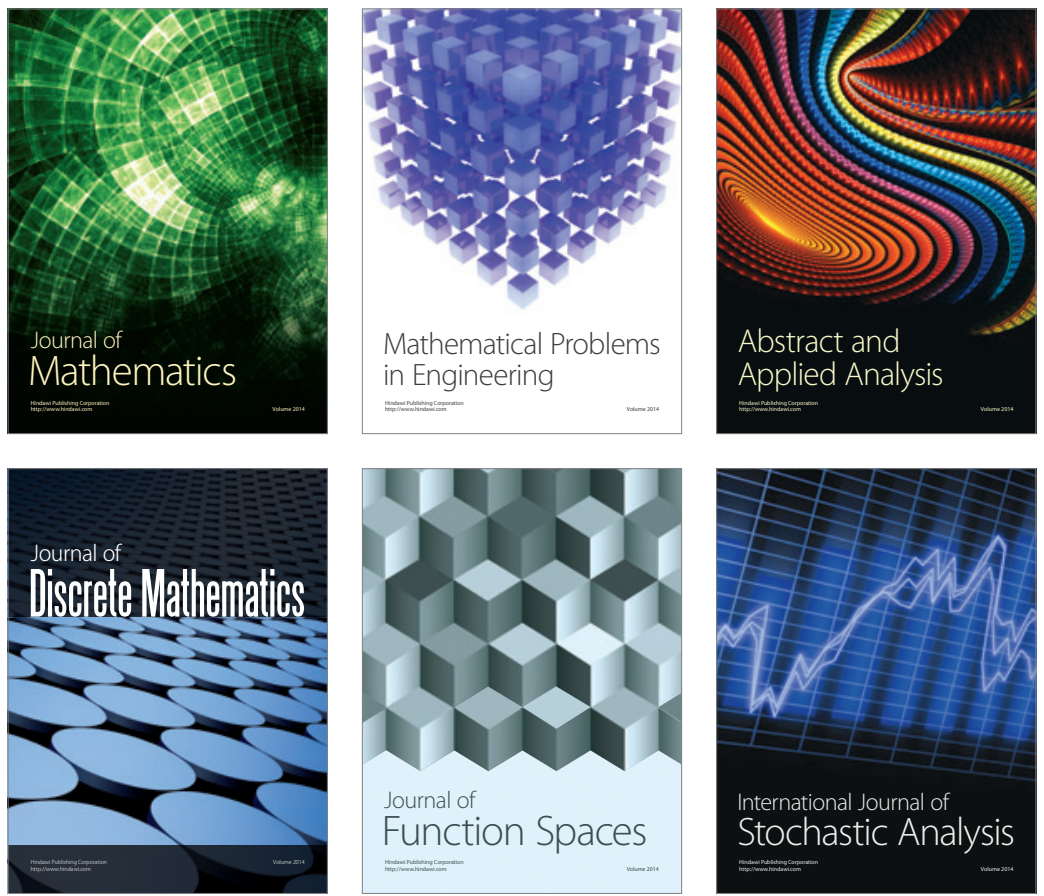

Journal of

Function Spaces

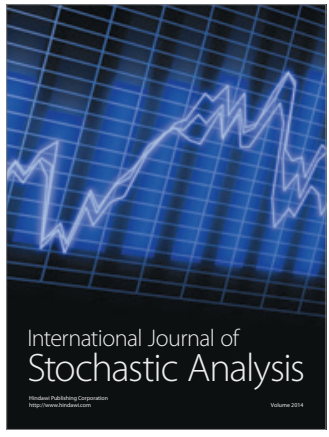

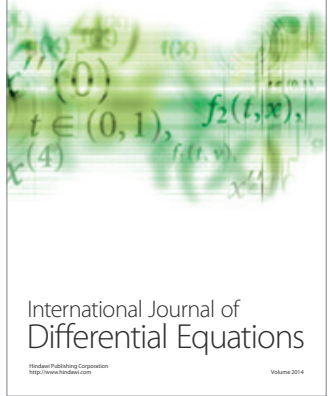
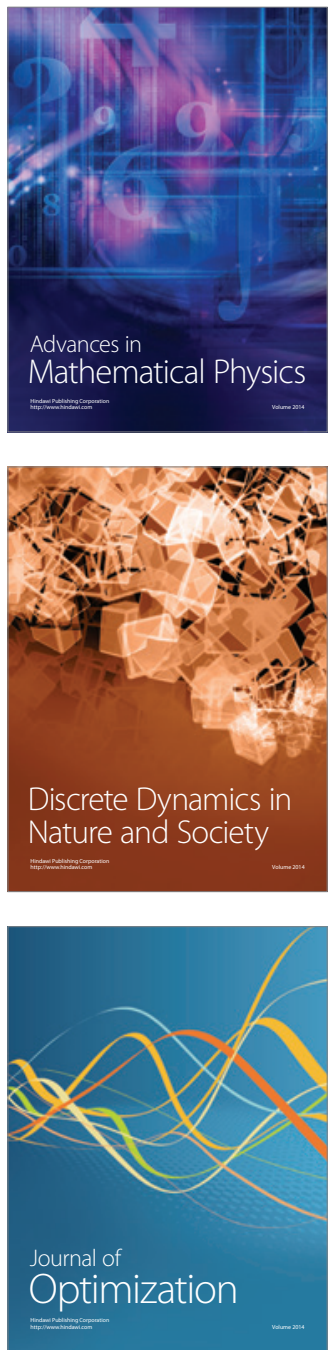